\title{
Estimation of Carbon Emissions of Domestic Energy Usage by Chinese Residents Based on Input - Output Method
}

\author{
Zhonglin Sheng ${ }^{1}$, Kan $\mathrm{Gu}^{2}$, and Weida $\mathrm{He}^{1}$ \\ ${ }^{1}$ Economics \& Trading Department, University of Science \& Technology Beijing, China \\ ${ }^{2}$ Chinalife Ecommerce Company Limited, China
}

\begin{abstract}
This paper will be based on the existing literature and research methods, with the 1980 to 2014 China's residential carbon emissions estimates. This paper mainly examines the changes in total residential carbon emissions and per capita carbon emissions, energy consumption per unit of household energy consumption, carbon emissions and energy composition of the above-mentioned analysis of urban and rural compared with the international comparison.
\end{abstract}

\section{Introduction}

From the concept of energy, energy as a carrier of energy and a basic source of power is an important input factor for economic growth. However, in the process of promoting economic growth, energy also generates a large number of environmental problems, which are determined by the nature of the energy itself (Smyth and Narayan, 2015). Therefore, energy (especially carbonbased energy) consumption will be accompanied by a large number of environmental pollution, especially carbon-based energy consumption generated by greenhouse gas emissions. From the perspective of energy properties, energy consumption is bound to have a certain amount of environmental pollution (except for clean energy) due to its inherent characteristics in promoting economic growth.

The relationship between energy consumption, carbon emissions and economic growth has become the focus of current research, which is caused by the global climate change caused by carbon emissions. Numerous studies show that the causes of global climate change lie in human energy consumption, which consumes a large amount of carbon-based energy during the course of economic growth, resulting in a large amount of carbon dioxide.

Kolstad and Krautkraemer (1993) pointed out that there is a dynamic relationship between environment, energy consumption and economic growth. They think the environment will be destroyed in the long run when the consumption of energy has immediate benefits for economic growth. Aaron Kearsley and Mary Riddel (2010) used carbon dioxide-based carbon oxide data from 27 countries in the OECD from 1980 to 2004 and nitrogen oxide data from 1990 to 2004 to study the relationship between environmental indicators and GDP per capita, degree of external relationship between development, and population. Based on the VAR model and the impulse response function analysis method, Ba Shusong and Wu Dayi (2010) quantitatively analyzed the total energy consumption and the four main pairs of energy consumption (coal, oil, electricity and natural gas) by building a model of $\mathrm{CO} 2$ emission reduction cost calculation Impact of macroeconomic variables (output, investment, employment). Niu Shuwen et al. (2010) analyzed the relationship between energy consumption, GDP and CO2 emissions from 1971 to 2005 using the panel data model for the eight Asia-Pacific countries. The results show that there is a long-term equilibrium relationship among the three. Based on energy statistics from 1978 to 2007, Huo Zongjie and Zhou Caiyun (2010) conducted a causal and cointegration study on China's economic growth, energy structure and energy consumption and found that there is a one-way economic growth in China to energy consumption and The causality of energy structure, and the two-way causal relationship between energy structure and energy consumption, the impact of short-term and long-term energy structure on energy consumption should be greater than the impact of economic growth on energy consumption.

The calculation of carbon emissions for residential use is calculated by calculating the amount of carbon emitted by burning fossil fuels in residential areas. In this study, the living energy of residents will be classified into five categories, namely coal (including gas), petroleum (including kerosene and liquefied petroleum gas), natural gas, electricity and heat. Among them, the consumption of fossil fuels such as coal, oil and natural gas is the terminal consumption of primary energy, and its carbon emissions can be calculated based on the carbon emission factors of various types of energy sources.

\section{Data \& Methods}


Electricity and heat consumption is secondary energy consumption. The calculation of carbon emissions needs to distinguish between fossil energy consumption contained in energy production, conversion and end-use consumption. As the composition of electricity, including thermal power, hydropower, nuclear power, wind power, etc., need to be separated from the thermal power and extract and decomposition of various types of fossil fuels for thermal power consumption components. Thermal energy consumption also need to do decomposition of fossil energy composition. Therefore, the carbon emissions of residential energy use can be divided into two parts: the secondary energy conversion of fossil fuels in energy use for life and the corresponding carbon emissions from energy loss. Among them, the power consumption is calculated based on the standard annual rate of thermal power generation on the basis of the calculation method of power generation using the standard amount of conversion. Specific calculation methods and formulas are as follows.

$$
\begin{aligned}
C E & =C E_{f e}+C E_{s e} \\
& =\sum_{p=1}^{p}\left(k_{p} \times E C_{f e \_p}\right)+\sum_{p=1}^{p}\left(k_{p} \times \sum_{q=1}^{Q} E C_{t e \_p \_q}\right) \\
& =\sum_{p=1}^{p}\left(k_{p} \times E C_{f e \_p}\right)+\sum_{p=1}^{p}\left(k_{p} \times E C_{t e \_p}\right) \\
& =\sum_{p=1}^{p}\left[k_{p} \times\left(E C_{f e \_p}+E C_{t e \_p}\right)\right]
\end{aligned}
$$

In the formula, each variable is set as follows: $C E$ is the carbon emissions of energy used for life; $E C$ is the energy consumption of living; and $k$ is the carbon emission factor of energy. Each variable subscript is set as follows: $f e$ is the primary energy; $s e$ is the secondary energy; te is the converted energy; $p$ is the primary energy type number; $q$ is the secondary energy species number.

The data on domestic energy used in the study come from the "China Energy Balance Sheet" in the "China Energy Statistical Yearbook" in the relevant year. In the early 1980 s, the data on domestic energy use in some years lacked statistics of urban and rural areas and did linear interpolation. The standard amount of all kinds of energy physical data conversion using "China Energy Statistical Yearbook 2008" attached to "a variety of energy standard coal reference coefficient." The standard amount of electricity and energy conversion using standard coal consumption method. Various types of energy carbon emission factor using the National Development and Reform Commission Energy Research Institute (2003) to provide the data.

\section{Results}

The data of the carbon emission of domestic and rural residents from 1980 to 2014 obtained from the calculation method formula shown in the previous section are shown in Table 1. The raw data used in this section are all from the relevant years of the National
Bureau of Statistics China Energy Statistical Yearbook and China Statistical Yearbook.

In general, the total amount of carbon dioxide emissions from domestic consumption shows a rapid upward trend. From 1980 to 2014, domestic carbon emissions increased from 67.28 million tc to 224.103 tc, an increase of $164.9 \%$. Over the same period, China's per capita household energy consumption increased from 68 $\mathrm{kgC}$ to $204 \mathrm{kgC}$, an increase of $87.2 \%$. Household carbon emissions per household increased from $314 \mathrm{kgC}$ to $687 \mathrm{kgC}$, an increase of $28.23 \%$ (Figure 1). At this stage, the general feature of the increase in carbon emissions of domestic energy consumption is that the growth rate of per capita emissions is much lower than the total growth and the average growth rate per capita is far lower than the growth rate of per capita. Among them, from 1999 to 2003, the per capita carbon emissions from household energy use showed a negative growth compared with 1980. On the one hand, this is related to the declining household size of our households leading to a decline in energy consumption per household. On the other hand, due to the impact of the Asian financial turmoil, energy supply was tight during this period. Frequent "coal shortage" and "power shortage" The overall decline in consumer spending may affect household consumption.

From the perspective of household energy consumption and changes in the proportion of its carbon emissions in the total energy consumption of the industry (Fig. 1.), from 1980 to 2010, household energy use and its carbon emissions accounted for energy consumption and total carbon emissions. The proportion of overall decline. The proportion of domestic energy consumption dropped from $15.26 \%$ to $9.86 \%$, while the proportion of domestic carbon emissions dropped from $18.02 \%$ to $9.94 \%$ over the same period. This shows that in the past 30 years, China's energy consumption and corresponding increase in carbon emissions mainly come from the industrial sector. In contrast, the direct energy consumption of residents lives at a relatively low level.

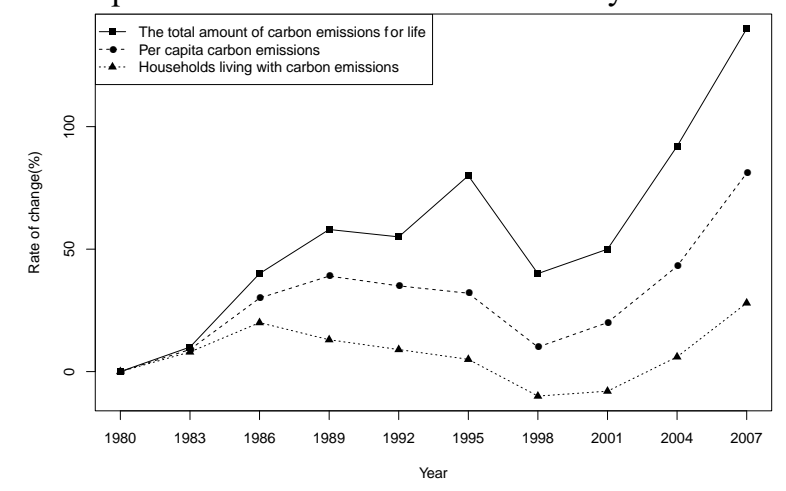

Fig. 1. China's residential energy consumption rate of change of carbon emissions.

It is noteworthy that in the past 30 years, the proportion of household carbon emissions to total carbon emissions has been consistently higher than the proportion of household energy consumption to total energy consumption over the same period, with a maximum difference of $3.02 \%$, indicating that the Stage 
of China's residential energy consumption per unit of

wide carbon emissions. Some reasons are as follows:

energy consumption slightly higher than the industry-

Table 1. China's urban and rural residents living with carbon emissions.

\begin{tabular}{|c|c|c|c|c|c|c|}
\hline Year & $\begin{array}{c}\text { Living } \\
\text { energy } \\
\text { consumption } \\
(\mathbf{1 0 0 0 0 / \text { tce } )} \\
\end{array}$ & $\begin{array}{l}\text { Living Energy- } \\
\text { use carbon } \\
\text { emissions } \\
(10000 / \text { tC) } \\
\end{array}$ & $\begin{array}{c}\text { Per capita } \\
\text { carbon } \\
\text { emissions } \\
(\mathrm{kgC}) \\
\end{array}$ & $\begin{array}{c}\text { Average } \\
\text { Households } \\
\text { living carbon } \\
\text { emissions (kgC) } \\
\end{array}$ & $\begin{array}{c}\text { Urban per capita } \\
\text { energy consumption } \\
\text { of carbon emission } \\
(\mathrm{kgC})\end{array}$ & $\begin{array}{c}\text { Rural per capita } \\
\text { energy consumption } \\
\text { of carbon emissions } \\
(\mathrm{kgC}) \\
\end{array}$ \\
\hline 1980 & 9195 & 6728 & 68 & 314 & - & - \\
\hline 1985 & 12762 & 9273 & 88 & 379 & 208 & 50 \\
\hline 1990 & 14775 & 10546 & 92 & 362 & 193 & 56 \\
\hline 1991 & 15937 & 11376 & 98 & 382 & 202 & 60 \\
\hline 1992 & 15566 & 11022 & 94 & 362 & 182 & 61 \\
\hline 1993 & 15165 & 10635 & 90 & 342 & 168 & 59 \\
\hline 1994 & 15326 & 10609 & 89 & 335 & 158 & 60 \\
\hline 1995 & 15653 & 10699 & 88 & 331 & 158 & 61 \\
\hline 1996 & 17558 & 12062 & 99 & 366 & 166 & 69 \\
\hline 1997 & 16214 & 10908 & 88 & 321 & 149 & 60 \\
\hline 1998 & 14228 & 9350 & 75 & 272 & 127 & 49 \\
\hline 1999 & 14916 & 9827 & 78 & 280 & 128 & 52 \\
\hline 2000 & 15611 & 10142 & 80 & 275 & 129 & 52 \\
\hline 2001 & 16215 & 10349 & 81 & 277 & 125 & 54 \\
\hline 2002 & 17248 & 11000 & 86 & 290 & 128 & 58 \\
\hline 2003 & 19382 & 12530 & 97 & 328 & 141 & 67 \\
\hline 2004 & 20715 & 13248 & 102 & 337 & 142 & 73 \\
\hline 2005 & 22792 & 14617 & 112 & 362 & 150 & 83 \\
\hline 2006 & 24742 & 15780 & 120 & 381 & 161 & 88 \\
\hline 2007 & 26180 & 16545 & 125 & 397 & 167 & 91 \\
\hline 2008 & 27255 & 17080 & 132 & 426 & 185 & 97 \\
\hline 2009 & 28197 & 18505 & 139 & 482 & 193 & 102 \\
\hline 2010 & 29943 & 19065 & 154 & 501 & 209 & 109 \\
\hline 2011 & 30267 & 19848 & 162 & 588 & 266 & 118 \\
\hline 2012 & 32596 & 20314 & 178 & 601 & 297 & 135 \\
\hline 2013 & 34915 & 21786 & 191 & 653 & 314 & 156 \\
\hline 2014 & 36548 & 22403 & 204 & 687 & 331 & 167 \\
\hline
\end{tabular}

Firstly, the energy structure of residential energy consumption in this period is inferior to that of the whole industry; secondly, some of the fossil energy used as raw materials in the industrial sector is included in the total energy consumption but not included in the carbon emission calculation, which Making the whole industry's unit of energy consumption carbon emissions may be lower than the living energy of carbon emissions. The difference generally showed a decreasing trend year by year and dropped below $0.4 \%$ after 2000 . It can be considered that at present, the energy consumption per unit of energy consumed by residents living in China is basically at the same level as that of the entire industry.

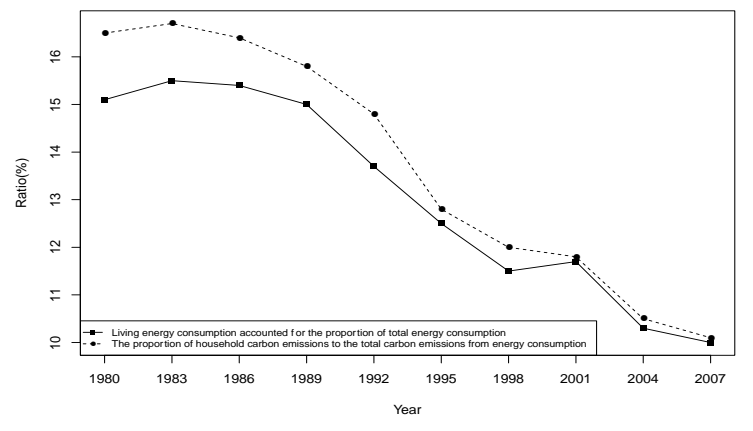

Fig. 2. Household energy use and its share of carbon emissions in energy consumption and its share of total carbon emissions (Partial). 
At the same time, the structure of household energy consumption in our country is gradually optimized, which can be confirmed from the composition of consumption carbon emissions of household energy consumption terminals. As shown in Fig. 3., from 1980 to 2014, the proportion of emissions from end-uses of household consumption of carbon emissions from household end-use consumption decreased from 91.86\% to $26.35 \%$ annually, while the share of electricity consumption in emissions from $4.41 \%$ to $47.56 \%$. This is in line with the great progress made by China's power industry since the reform and opening up.

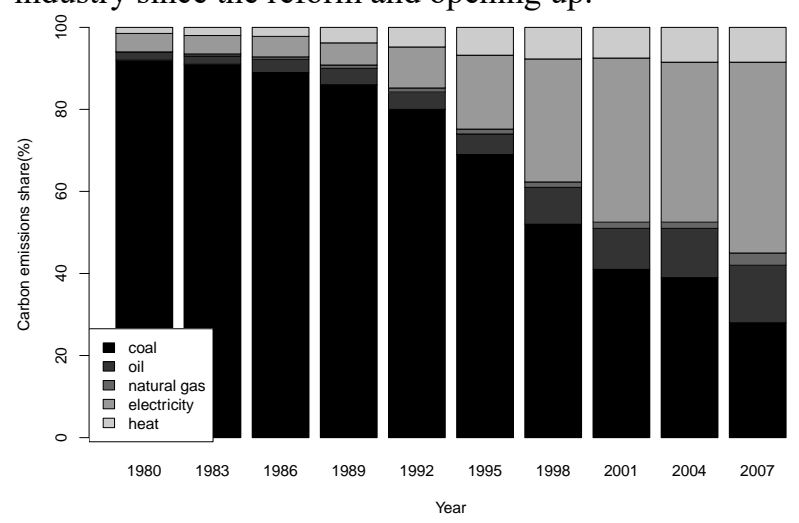

Fig. 3. Consumption of household energy consumption by the end of carbon emissions (part).

From 1980 to 2014, China's residential energy consumption increased from 91.95 million tce to 263.82 million tce, an increase of $186.72 \%$, corresponding to an increase of $145.90 \%$ of that of domestic energy use, indicating that the increase in carbon emissions for domestic energy use Much lower than the corresponding increase in energy consumption. Further examining the energy consumption of residential energy consumption per unit of carbon emissions (Fig. 4.), we can see that this phase of energy consumption of household energy consumption remained the overall trend of carbon emissions decreased from $0.732 \mathrm{tC} /$ tce in 1980 to 0.548 tC/tce in 2014 , a decrease of $13.82 \%$. The reduction of carbon emission per unit of energy consumption directly leads to the decrease of the increase of carbon emissions for domestic residents in this stage.

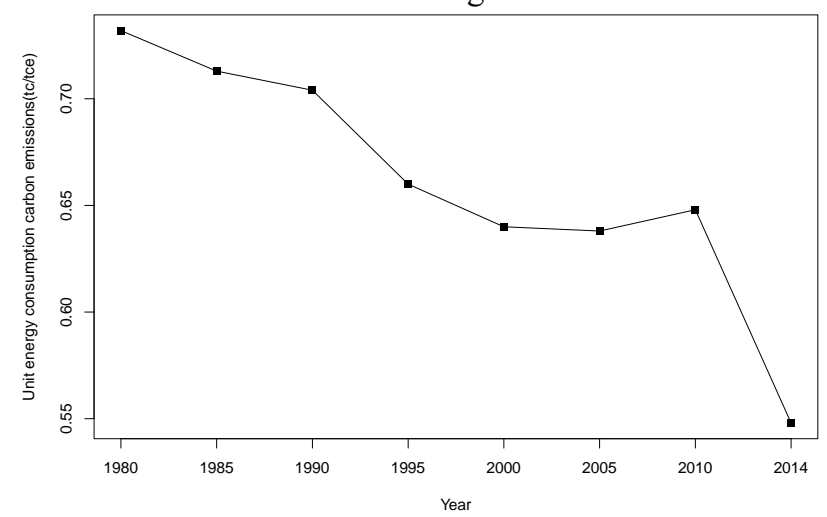

Fig. 4. Residential energy consumption per unit of carbon emissions trends.

In general, carbon emissions per unit of energy consumption are mainly related to energy structure and technological progress. From the above energy structure changes of living energy use, the continuous decline in the proportion of coal contributes to the reduction of carbon emissions per unit of energy consumption. From the perspective of technological progress, from the calculation of the standard coal consumption rate of thermal power plants over the years. The average coalfired power consumption rate for thermal power generation that decreased by $0.496 \mathrm{kgce} / \mathrm{kWh}$ at this stage decreased to $0.344 \mathrm{kgce} / \mathrm{kWh}$, a decrease of $30.70 \%$. It can be considered that the reduction of energy consumption carbon emissions of domestic residential units during this period is the result of joint actions of energy structure adjustment and energy technology advancement.

\section{Conclusion}

From 1985 to 2014, the proportion of coal consumed by urban residents dropped from $86.58 \%$ to $13.47 \%$. The proportion of electricity rose sharply while the proportion of oil, natural gas and heat continued to rise. Currently, electricity is the main factor Nearly 50\%), other energy each about one to two into the pattern of living energy. At this stage, the average per capita consumption of urban residents showed a downward trend followed by a rise, with a generally stable fluctuation. As a result, the decline in carbon emissions per capita of urban residents is mainly due to the optimization of energy structure. Over the same period, structural changes in rural residents' energy use mainly represented a continuous decline in the proportion of coal, a substantial increase in the proportion of electricity, a slight increase in the proportion of oil, and natural gas and thermal consumption were almost empty, forming the current power and coal-based energy. The proportion of $51.11 \%$, respectively, $40.87 \%$ ) of life energy structure. In the same period, the consumption per capita of rural residents rose in a fluctuating trend, nearly doubling the overall increase. Therefore, despite the adjustment of energy structure, the per capita carbon emission of rural residents

has continued to rise.

The differences in energy structure directly lead to the differences of urban and rural residents in terms of energy consumption per unit of energy consumption. From 1985 to 2014, the energy consumption of urban residential units decreased from $0.73 \mathrm{tC} /$ tce to $0.57 \mathrm{tC} /$ tce, while that of rural residents dropped from $0.72 \mathrm{tC} /$ tce to $0.67 \mathrm{tC} /$ tce. This shows that after nearly 30 years of development, the energy consumption per unit of energy consumed by urban residents is better than that of rural residents. For relatively high-carbon coal, per capita

consumption of urban residents is lower than that of rural residents; for low-carbon natural gas, the per capita consumption of urban residents is much higher than that of rural residents; while for the consumption of electricity with declining standard energy consumption, Per capita consumption is also higher than that of rural residents. 
The three factors combine to make the consumption structure and energy efficiency of urban residents better overall than that of rural residents and the difference of

\section{References}

1. S. Russell, N.P. Kumar, Energy Economics, 50, 351358 (2015)

2. C.D. Kolstad, J.A. Krautkraemer, Handbook of Natural Resource and Energy Economics, 3, 12191265 (1993)

3. S. Ba, D. Wu, Economics and Management Research, 6, 5-11 (2010)

4. S. Niu, Y. Ding, Y. Li, G. Luo, Y. Niu, China Soft Science, 5, 12-19 (2010)

5. Z. Huo, C. Zhou, Contemporary Economic Management, 32, 10-14 (2010)

6. W. Nordhaus, The climate casino: Risk, uncertainty, and economics for a warming world (2013) energy consumption carbon emission level of urban and rural residents.

7. N.C. Onat, M. Kucukvar, O. Tatari, The International Journal of Life Cycle Assessment, 19, 1488-1505 (2014)

8. G.P. Peters, G. Marland, E.G. Hertwich, L. Saikku, A. Rautiainen, P.E. Kauppi, Climatic Change, 97, 34 (2009)

9. G. Seyfang, A. Smith, Environmental Politics, 16, 584-603 (2007)

10. B. Su, B.W. Ang, Applied Energy, 114, 377-384 (2014)

11. C.F. Tang, B.W. Tan, Quality \& Quantity, 48, 781797 (2014). 